\title{
Web-Qwest as a Form of Organization of Independent Work of Students
}

\author{
Elena Zhestkova \\ Faculty of preschool and primary \\ education \\ Lobachevsky State University of \\ Nizhny Novgorod (Arzamas \\ Branch). \\ Arzamas, Russia \\ ezhestkova@mail.ru \\ Elena Gubanihina \\ Faculty of preschool and primary \\ education \\ Lobachevsky State University of \\ Nizhny Novgorod (Arzamas \\ Branch). \\ Arzamas, Russia \\ gubanihiny@yandex.ru
}

\author{
Dmitriy Gusev \\ Faculty of preschool and primary \\ education \\ Lobachevsky State University of \\ Nizhny Novgorod (Arzamas \\ Branch). \\ Arzamas, Russia \\ dimigus@rambler.ru \\ Elena Klyueva \\ Faculty of preschool and primary \\ education \\ Lobachevsky State University of \\ Nizhny Novgorod (Arzamas \\ Branch). \\ Arzamas, Russia \\ klyueva.lena@list.ru
}

\author{
Natalja Kudakova \\ Faculty of preschool and primary \\ education \\ Lobachevsky State University of \\ Nizhny Novgorod (Arzamas \\ Branch). \\ Arzamas, Russia \\ kkudakova@mail.ru \\ Faina Povshednaya \\ Faculty of preschool and primary \\ education \\ Nizhny Novgorod State \\ Pedagogical \\ University K. Minina. \\ Nizhny Novgorod, Russia \\ povshedfv@yandex.ru
}

\begin{abstract}
The article is devoted to the organization of independent work of students enrolled in the direction of teacher training based on web quests. An example of an educational web quest for the 3rd year is the "Inclusive School".

One of the leading directions of development of the system of higher pedagogical education is the strengthening of the practice-oriented orientation of the study of disciplines, including the educational cycle. This concerns not only an increase in the share of active and interactive methods in teaching, an increased attention to organizing and conducting internships in educational institutions, but also a change in the approach to organizing independent work of bachelor students. Much attention is increasingly given to increasing the level of information and communication competence of future teachers (electronic libraries and educational Internet portals are the main source of educational information for modern students), it is advisable to use information and communication technologies as an organizational and substantive basis for independent work.
\end{abstract}

This approach to the organization of independent work involves the development of tasks by teachers using Internet technologies, which, depending on the type of task, can be performed online or offline. Tasks for independent work can be directed to an independent search in the network with the subsequent processing of information about a specific problem; on the organization of interaction in the network; create web pages; conduct educational research, social or educational projects. The forms for presenting the results may also vary: text documents (with hyperlinks), databases of multimedia presentations, web pages, web quests.

Particular attention, in our opinion, should be paid to teaching real web quests. A web quest is considered as an activity-oriented didactic model that provides for students' independent search work on the Internet.

As a form of organizing independent work, a web quest has several advantages, including: increased student motivation; activation of individual or group activities; more efficiently use the understanding of the time allotted for independent work of students; the ability to not only integrate different types of assignments and forms of providing results, but also to vary the level of difficulty of the task for independent work, the duration of implementation, the number of performers.

Keywords - Educational web-quest, independent work of students, teacher training.

\section{INTRODUCTION}

In the modern educational situation, one of the qualification requirements for the future teacher is the ability to independently master knowledge in various fields, to engage in self-education.

The most important means of forming students of all types of cognitive activity is the performance of various types and types of self-learning by them. Independent work in the modern educational process is considered as a form of training organization that is able to provide an independent search for the necessary information, creative perception and understanding of the educational material obtained during the classes. It involves the use of various forms of cognitive activity of students in the classroom and after school hours, the development of analytical skills, control skills and planning training time, the development of skills and rational organization of educational work [1]. Thus, independent work is a form of organization of the educational process, stimulating the activity, independence and cognitive interest of students.

Independent work of students using information 
technology, Internet technology is an active method of learning, in which students, in accordance with the instructions of the teacher and under his guidance, not only solve the learning task, but also receive the necessary computer skills with various types of information [2], [3]. The activity of this method is determined, first of all, by the goal that is realized by the student during his independent work, it becomes relevant and significant for him, there are motives for the activity:

- the need to expand knowledge, learn new things;

- master the ability to work using a computer;

- the desire to show independence, to perform the task without outside help;

- the need to test your knowledge;

- the possibility of public presentation of the results of activities.

In order to improve students' self-study, constant work is being carried out to select the most effective self-learning organization technologies that, based on the interests, individual characteristics, type of thinking and educational needs of students, will contribute to mastering general and professional skills, including information and communication [4].

Considering that the majority of students spend most of their time in the virtual space, on the Internet, it is advisable to organize the execution of their own tasks in their usual environment. When organizing extracurricular independent work, it is truly independent, since the student himself determines the place and time of inclusion in the educational process [5], [6].

One of these technologies is a web quest. This technology contributes to increasing students' interest in the subjects being studied, their ability to work with information placed on various media, as well as the ability to plan their activities independently [7].

Analysis of scientific sources suggests that the web quest is considered as a form, tool and method of education [8], as a technology, problem task [9] and even as an Internet site, with which students work, solving a particular educational task. According to A. Shestakova, a web quest is an authentic learning technology that allows students to build their own concepts based on the study of the information provided, to create practiceoriented projects [10]. This is explained by the following signs of web quests: unlimited educational resources, the connection of educational material with real life, the active involvement of students in research activities, the advisory role of the teacher in the process of independent work of students.

In our opinion, the web quest is a problem-based learning technology that combines a set of specific methods and tools, including a game and a project method, and involves the active use of information and communication technologies to solve interdisciplinary educational problems [11], [12].

\section{Materials AND METHODS}

The main research methods used in the work should include: a theoretical analysis of psychological, pedagogical and methodological literature; comparison, synthesis, systematization of the activities of educational institutions in the field of arts and crafts; modeling the content of the educational web-quest, the study and synthesis of the pedagogical experience of teachers of rural educational institutions; observation of the surrounding educational environment in order to design the use of folk arts and crafts.

\section{RESULTS AND DISCUSSION}

In the context of the socio-economic reorganization of Russian society, the introduction of innovative highprecision production technologies into various spheres, the system of national education is being modernized. Special changes have occurred in the system of primary and basic general education, firstly, due to the entry into force on September 1, 2013 of the Federal Law "On Education in the Russian Federation", and, secondly, due to the implementation of the new federal state standards general education. One of the strategic objectives of the new Law and the standard can be considered the continuity of the implementation of educational programs of primary, basic and secondary education using e-learning and distance learning technologies.

Among the basic ideas embodied in the exemplary curriculum for school subjects for the first stage of general education, based on the requirements of the new standard, the rethinking of the essence and meaning of the fine arts in elementary school draws attention. Fine art is a basic subject now, aimed mainly at the formation of the emotional and imaginative, artistic type of thinking, which is a condition for the development of the intellectual and spiritual activity of a growing personality.

As educational practice shows, the results of school monitoring, as well as the opinions of many scientists, one of the favorite activities in elementary school that significantly affect the amplification of child development, is decorative and applied, implemented in art classes in accordance with the GEF using electronic educational and information resources. Despite the fact that electronic resources began to appear in a rural school at the end of the 20th century, the full-fledged organization of the educational process with the use of information technologies began to be carried out quite recently, and not everywhere.

It should be noted that the use of electronic resources, according to researchers in the modern educational process of both urban and rural schools, is actively implemented mainly on the subjects of the natural-mathematical cycle, unfortunately, they are not fully utilized in humanitarian subjects of the aesthetic cycle. Today, in a village school, more than ever, it is important to apply modern electronic resources on aesthetic-oriented subjects, which will allow solving several important problems in the district educational environment [13].

First, schoolchildren's training in fine arts, crafts, music and technology based on electronic and distance learning will make it possible to solve the personnel 
problem in rural schools. But there are no many teachers specializing in a specific field of art in these schools and, based on the number of students in schools, they will not be presented for a long time.

Secondly, the rural school is far from the social and cultural opportunities of big cities, in the village the sources of culture were exhausted for a number of reasons, that's why the great difficulties cause in educational work with children. Today there is one of the few jewels in the village, the secret of which is inherited in every family. This invaluable "phenomenon" is popular applied art created by a simple local resident without a special education for this purpose. Almost in every rural school, house of creativity, club there is a museum where valuable information on applied arts and folk culture is stored, which characterizes the identity and nationality of the settlement. In modern conditions, it is simply necessary to "bring" this information into the school's electronic resource, so that in the future it will be possible to exchange experiences of folk art through the local district network or in any other way, to fully educate children in the village.

With the use of electronic and distance learning resources, it is possible to organize work on folk applied arts with students of rural schools in various forms, going beyond the school organization by connecting to the information network of other schools. So, at the faculty of preschool and primary education of the Arzamas branch of UNN, much attention is paid to preparing future teachers for work in rural areas, one of the directions of such training of students is mastering ICT competence in the field of applied arts. Students learn to independently organize work with students of rural schools in the field of folk arts and crafts through various forms of electronic and distance learning resources [14].

One of such forms of work with rural schoolchildren in applied creativity can be a web-forum, in which the information base accumulates, the students, using this form of work, organize inter-school communication in a particular area of art.

Another form of students' work with students in the field of folk art can be a virtual conference on the exchange of experience, on summarizing the results of work in a specific form of productive activity.

Conducting virtual presentations, exhibitions, competitions and contests are effective forms of work of students with schoolchildren of great educational value.

Another form of work with rural schoolchildren in applied creativity using electronic resources can be a virtual lesson, conducted at a certain time, as a teacher of visual arts at the same time in computer classes at several regional schools.

The organization of out-of-class work in a rural school can also be carried out in the form of virtual excursions on the species diversity of folk art and much more.

Let us dwell in more detail on the innovative project - the web quest "Folk applied arts in a rural school", developed in the scientific laboratory of the didactics of the rural school of the Arzamas branch of UNN, aimed at exploring the possibilities of using electronic and distance learning technologies to improve the organization of the educational process of the rural school.

A web quest is a form of organizing self-study with students; they implement this project as part of writing course works, while undergoing various types of practices, while preparing final qualifying works, as part of studying individual disciplines in preparation for laboratory and practical classes in various disciplines.

Structurally, the web-quest "Decorative and Applied Creativity (DPT) in a Rural School" includes several sections, its visual presentation is shown in Figure 1, the first of which should be considered the section on the regional traditions of decorative and applied creativity in the village. The main content of this section is the text with the names of the types of applied art, which are typical for the villagers, photo of needlework and text relating to the authors of the products.

In the system aspect, the quest includes the following components: targeted, structural, informative and functional.

The quest is intended, above all, to accumulate experience in the use of folk arts and crafts in working with the children of the municipality: district, region, republic, federation. Its purpose is multifaceted.

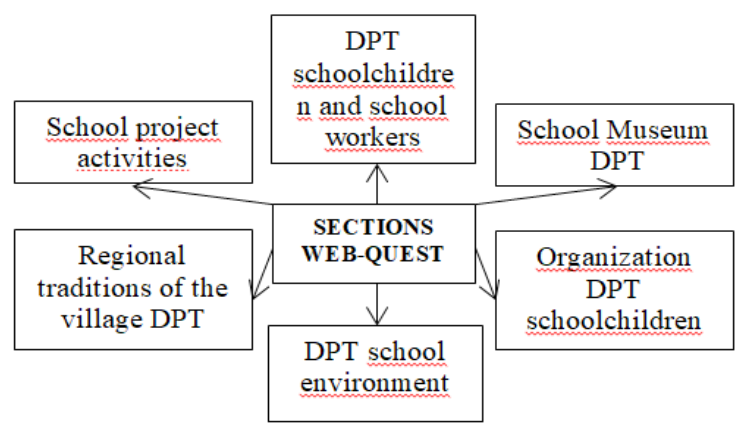

Fig. 1. The structure of the web-quest

In general cultural terms, the quest should contribute to the preservation and further development of the traditions of folk applied arts of rural residents. Peasant art, partly lost by our contemporaries, will receive additional impulses for further improvement of work, and in some cases, the revival of many half-forgotten or non-functioning "centers" of folk culture in rural society.

In socio-economic terms, the quest will contribute to the involvement of villagers in socially useful productive work, bringing personal benefits and material well-being. Having conducted a historical insight into the essence and purpose of folk crafts in the life of a rural resident, it can be safely concluded that this kind of practical activity has not lost its significance to this day since the emergence and development of settlements in the Russian hinterland. Indeed, for many settlements, this primordial occupation was sometimes and is the only source of both material 
and spiritual benefits.

In the educational terms, access to the quest materials will allow to learn a new area of artistic and aesthetic knowledge, knowledge about the species diversity of folk art. Applied creativity is a natural occupation of people for almost every village. The teacher in the village, in his historical mission, is the custodian and repeater of local unique traditions. However, in practice, for several reasons, the teacher is not always ready to fulfill this mission. In such cases, the electronic resource of the album will provide indispensable assistance to teachers in the resumption of the school traditions of arts and crafts.

In the didactic aspect, quest resources can be used as visual illustrative material for classes in subjects. On the lessons of the Russian language and literature, relying on visualized electronic images of folk art can be given tasks for schoolchildren: composing a story about a folk product, describing it verbally, analyzing special words such as "matryoshka", "weaving", "potter", etc., on the composition, the drafting of a proposal on any kind of applied arts. At fine art lessons an electronic album can be used as a means of visual-illustrative communication of students with works of applied art, during this process they become acquainted and draw various types of folk art. At the lessons of artistic work, you can use the content of the album as technological charts, explaining the sequence of creating folk products. Even in the lessons of mathematics, images of applied creativity can be used, for example, when schoolchildren become acquainted with arithmetic, when they explain the essence of the operations of addition and subtraction, and when teaching them how to solve various subject problems. In this case, the teacher or schoolchildren speak the content of the task using special terminology, which in itself ensures the involvement of elements of decorative and applied art in the educational process in the classroom.

From the spiritual and moral point of view, the use of quest materials will contribute to the improvement of rural society. Education or the healing of the human soul is not a momentary action with an obvious result, but a long process of systematic and consistent communication of a person with goodness, beauty and creation. The integration of these three components lies in the works of decorative art. Decorative scenes are filled by goodness, artistic images are the embodiment of true human values. Beauty is reflected in the subordination of the form, color and content of the folk product. The idea of creation, in fact, is the leitmotif of all creativity, including decorative and applied arts. A small person surrounded by beauty, goodness and creation, for the most part, will never be a manifestation of ugly, evil and destructive in adult life. That is precisely why the value of folk art in the artistic and aesthetic education of rural schoolchildren is so invaluable.

\section{CONCLUSION}

Constructively, the web-quest "Decorative and Applied Creativity in a Rural School" includes several sections, in the first of which it is advisable to consider a section on regional traditions of decorative and applied creativity in the village. Another important component of the web quest is the section of decorative and applied arts of students and school staff, the content of which is: product photos; texts with the name of the type of creativity, a list of materials necessary for its implementation; with the name and surname of the author.

The section on the organization of arts and crafts of schoolchildren, as a component of the quest, contains information relating to: circles, exhibitions, competitions of arts and crafts creativity.

Another important component of the quest can be a section on the project activities of rural schoolchildren in the field of arts and crafts. The content of the quest should contain information about the school museums of arts and crafts. An essential attribute can be a photo gallery of works from previous years.

Structurally, one should adhere to the fact that the web quest should be the same for all schools in terms of form and content. The amount of information is presented depending on the degree of study in a rural school of each described direction.

The presented web quest can be created on various online platforms. The content of such web quests will be the result of the work of students in the framework of certain types of work at the university. The creation of web-quests will, firstly, contribute to the improvement of the educational activities of the rural school on humanitarian subjects; secondly, the preservation, development and revival of a multinational folk culture; thirdly, generalization and popularization of a rural school in a separate subject area.

\section{REFERENCES}

[1] E.A. Zhestkova, Subject information and educational environment formation of information and communication competence of future professionals: environment. Technology. Resources: Proceedings of the 11th International Scientific and Practical Conference, june 15-17, 2017, vol. II, Rezekne: Rezekne Academy of Technologies, 2017, pp. 180-186.

[2] E. Zhestkova, E. Minaeva, N. Ivanova, O. Kolesova, and N. Lapin, "Teachers from different countries" Revista ESPACIOS, vol. 38(25), 2017, page 8. Available: http://www.revistaespacios.com/ a17v38n25/17382508.html

[3] E. Zhestkova, A. Akpayeva, N. Ivanova, T. Luchina, E. Minaeva, "Specifics of Educational Activity Anti-motivation in Future Teachers Subject to the Training Period," International Review of Management and Marketing, vol. 3, pp. 265-259, 2016.

[4] E. Zhestkova, Problematic approach to the study of literary disciplines in a pedagogical university: Society. Integration. Education. Proceedings of the International Scientific Conference, may 27-28, 2016, Rezekne: Rezeknes Academy of Technologies, 2016, pp. 286-299.

[5] E.R. Dikikh, On the use of social networks in education: Personality, family and society: issues of pedagogy and psychology: Sat. Art. on mater. XVI Intern. scientific-practical conf. Part I, Novosibirsk: SibAK, 2012

[6] O.A. Klimenko, Social networks as a means of learning and interaction of participants in the educational process: Theory and practice of education in the modern world: materials of the Intern. scientific conf, St. Petersburg, February 2012, SPb.: Renome, 2012, pp. 405-407. Available: https://moluch.ru/conf/ped/ archive/21/1799/ [Access April, 3, 2019].

[7] N.S. Kudakova, Media education of younger schoolchildren: Media and information literacy of a modern teacher: at 3 pm Part 1. 
Materials of the All-Russian Scientific and Practical Conference. Orenburg, Orenburg State Pedagogical University, october 30-31, 2018, Orenburg: Publishing house "Orenburg book", 2018. pp. 167-171.

[8] Y.S. Bykhovsky, Educational web quests [Electronic resource]: Proceedings of the international conference "Information technologies in education. ITO-99". Available: http://ito.edu. $\mathrm{ru} / 1999 / \mathrm{III} / 1 / 30015 . \mathrm{html}$ [Access June, 3, 2016].

[9] M.V. Andreeva, Technologies web quest in the formation of communicative and sociocultural competence: Information and communication technologies in teaching foreign languages: theses of reports of the I International Scientific and Practical Conference, 2004, pp. 20-25.

[10] A.Y. Shestakova, "Web quest as a new educational technology in high school," Scientific and technical statements of St. Petersburg GPU. Humanities and social sciences, vol. 2, pp. 64-68, 2012.

[11] E. Zhestkova, E. Gubanichina, S. Oparina, V. Sidorskaya, and D. Gusev, Interactive technologies as a means of forming general cultural and professional competencies among students of a pedagogical university: Society. Integration. Education. Proceedings of the International Scientific Conference, vol. I, may 26-27, 2017, Rezekne: Rezeknes Academy of Technologies, 2017. pp. 454-469.
[12] N. Kudakova, E. Gubanihina, E. Klyueva, T. Naumova, and E. Zhestkova, The pedagogical potential of information and communication technologies in the formation of ethnic and cultural awareness of younger schoolchildren: Vide. Tehnologija. Resursi - Environment, Technology, Resources 11. Cep. "Environment. Technology. Resources - Proceedings of the 11th International Scientific and Practical Conference", 2017, pp. 36-41.

[13] D. Gusev, S. Aksenov, R. Arifulina, T. Belyaeva, E. Ilaltdinova, I. Lebedeva, "In the search of national ideal of russian pedagogue," Journal of Entrepreneurship Education, T. 20. vol. 3, 2017.

[14] D. Gusev, E. Zhestkova, N. Kudakova, L. Filippova, F. Podshednay, Pedagogical potential of folk-applied creativity by means of ICT in the process of formation of educational and cognitive interest of younger students: Society. Integration. Education. Proceedings of the International Scientific Conference, vol. II, may 26-27, 2017, Rezekne: Rezeknes Academy of Technologies, 2017, pp. 93-108. 